\title{
PERANCANGAN USER INTERFACE (UI) \& USER EXPERIENCE (UX) APLIKASI PENCARI INDEKOST DI KOTA PADANGPANJANG
}

\author{
Ferry Fernando \\ Dosen Prodi Desain Komunikasi Visual ISI Padangpanjang \\ ferrydamara@gmail.com
}

\begin{abstract}
ABSTRAK
Indekost bisa disebut juga rumah penginapan. Itu adalah rumah yang digunakan orang untuk menginap selama 1 hari atau lebih, dan kadang-kadang untuk periode waktu yang lebih lama misalnya : minggu, bulan atau tahunan. Dahulunya, para penginapnya biasanya menggunakan sarana kamar mandi atau cuci, pantry dan ruang makan secara bersama-sama. Kehadiran indekost yang ada saat ini sangat memberikan manfaat yang besar bagi masyarakat terutama pemilik indekost dan pertumbuhan ekonomi Kota Padangpanjang Sumatera Barat. MYKOST merupakan aplikasi pencari indekost yang berada di Kota Padangpanjang. Aplikasi ini mempermudah masyarakat yang ingin mencari indekost dengan mendapatkan informasi mengenai alamat, harga, dan fasilitas secara mendetail. Selain itu berguna juga bagi para pemilik indekost untuk mendaftarkan indekostnya agar pendataan lebih teratur dan terpantau dengan baik. Secara solusi desain dipilihnya Perancangan User Interface (UI) \& User Experience (UX) sebagai pemecahan permasalahan untuk para pencari indekost agar bisa mengetahui informasi mendetail mengenai alamat, harga dan fasilitas dengan menggunakan smartphonenya. Perancangan user Interface \& user Experience ini berfungsi untuk mengkomunikasikan fitur-fitur sistem yang tersedia agar user mengerti dan dapat menggunakan sistem, serta memiliki nilai kepuasan dan kenyamanan dalam mengunakan aplikasi tersebut.
\end{abstract}

Kata Kunci: Indekost; Aplikasi MYKOST; User Interface; User Experience.

\section{PENDAHULUAN}

Indekost adalah sebuah jasa yang menawarkan sebuah kamar atau tempat untuk ditinggali dengan sejumlah pembayaran tertentu untuk setiap periode yang biasanya dihitung perbulan atau pertahun. Dari setiap indekost terdapat beberapa pilihan seperti memiliki 1 kamar tidur dan kamar mandi di dalam. Kemudian ada juga yang memiliki 1 kamar tidur, dapur dan kamar mandi dan masih banyak jenis lainnya.

Kehadiran indekost yang ada saat ini sangat memberikan manfaat yang besar bagi masyarakat terutama pemilik indekost dan pertumbuhan ekonomi Kota Padangpanjang. Indekost dirancang untuk memenuhi kebutuhan hunian yang bersifat sementara dengan sasaran pada umumnya adalah mahasiswa dan pelajar yang berasal dari luar kota ataupun luar daerah. Namun tidak sedikit pula, rumah kost ditempati oleh masyarakat umum yang tidak memiliki rumah pribadi dan menginginkan berdekatan dengan lokasi beraktifitas.

Oleh karena itu, fungsi Indekost dijabarkan oleh (MANDASARI, 2015) sebagai berikut: Sebagai sarana tempat tinggal sementara bagi mahasiswa yang pada umumnya berasal dari luar daerah selama masa studynya, Sebagai sarana tempat tinggal sementara bagi masyarakat umum yang bekerja di kantor atau yang tidak memeiliki rumah tinggal agar berdekatan dengan lokasi kerja, Sebagai sarana pembentukan kepribadian mahasiswa untuk lebih berdisiplin, mandiri dan bertanggung jawab, Sebagai tempat untuk menggalang pertemanan dengan mahasiswa lain dan hubungan social dengan lingkungan sekitarnya. 
Menurut Garis Panduan dan Peraturan bagi Perancangan Bangunan oleh Jawatan kuasa kecil piawaian dan kost, Indekost mahasiswa/pelajar dibedakan menjadi : Sistem 2 orang pada satu kamar (double room ); untuk double room, tempat tidur yang digunakan adalah tempat tidur tingkat ( double decker ) dan bila mahasiswa atau pelajar tersebut sudah masuk pada tingkatan yang lebih tinggi diperbolehkan untuk mengganti tempat tidur dengan tempat tidur terpisah ( twin decker ), Sistem satu orang satu kamar ( single room ); dimana hanya diperbolehkan satu pelajar pada tiap kamar, Sistem campuran antara ketiga system diatas, biasanya digunakan pada institute pada tingkat kebangsaan/antarbangsa. Indekost juga dapat dibagi berdasarkan pengelolaannya yaitu : Indekost bercampur dengan rumah pengelolanya, tetapi tetap dalam satu bangunan, Indekost yang berdiri sendiri dan mempunyai gedung sendiri khusus untuk mahasiswa dan pengelolanya tidak bertempat tinggal digedung tersebut secara bersamaan, Indekost yang bercampur dengan rumah kontrakan sehingga pengelola rumah kost mempunyai tempat khusus tetapi tidak dalam satu gedung. (MANDASARI, 2015)

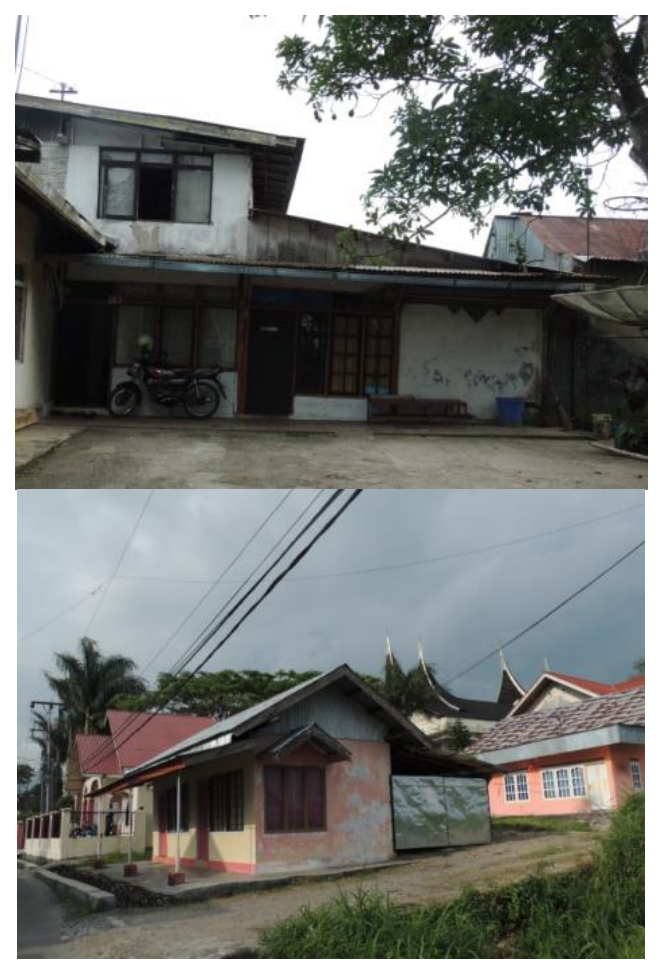

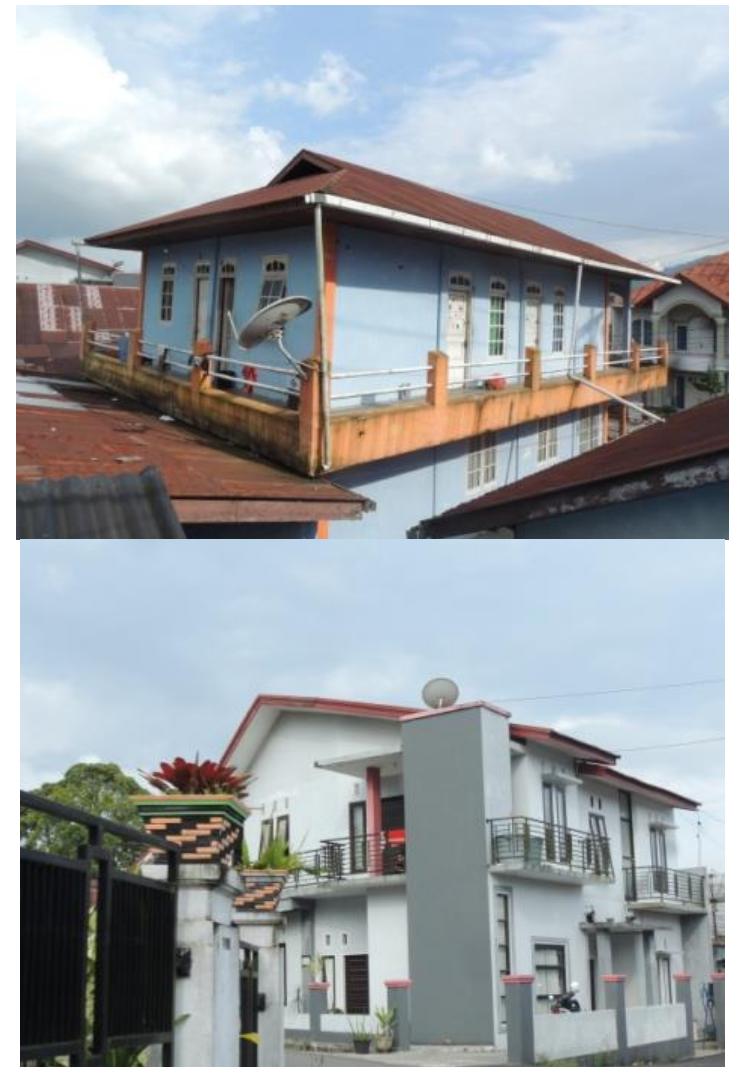

Gambar 1

Kondisi Beberapa Indekost Di Kota Padangpanjang

( Diambil Oleh ferry fernando, 2018 )

\section{METODE PERANCANGAN}

Menurut definisi dari ISO (International Organization for Stardardization) 9241-210, user experience adalah persepsi seseorang dan responnya dari penggunaan sebuah produk, sistem, atau jasa. User Experience (UX) menilai seberapa kepuasan dan kenyamanan seseorang terhadap sebuah produk, system, dan jasa. Sebuah prinsip dalam membangun $U X$ adalah khalayak mempunyai kekuasaan dalam menentukan tingkat kepuasan sendiri (costumer rule). Seberapa bagusnya fitur sebuah produk, sistem, atau jasa, tanpa khalayak yang dituju dapat merasakan kepuasan, kaidah, dan kenyamanan dalam berinteraksi maka tingkat $U X$ mejadi rendah. Perkembangan dunia digital dan mobile menjadikan $U X$ menjadi lebih konsisten. Kini seseorang dapat mengakses sebuah situs web dari berbagai piranti. Perancangan $U X$ mengalami ekspansi, karena pengalaman dalam sebuah piranti akan berbeda dengan 
piranti lainnya. Mengakses web dari komputer desktop akan berbeda dengan mengakses web yang sama lewat smart phone. Begitu juga media digital yang ditampilkan semakin beragam dengan hadirnya sosial media. Namun dalam hal content delivery sebuah brand harus mengeluarkan satu bahasa yang sama di berbagai channel dan media. Untuk itu konsep $U X$ perlu dipelajari lebih lanjut agar komunikasi brand tetap solid dan fokus.

Menurut Satzinger, Jackson, dan Burd (2012, p189), User Interface adalah input dan output yang langsung melibatkan sistem pengguna akhir. Antarmuka pengguna dapat digunakan langsung oleh pengguna internal atau eksternal sistem. Desain dari user interface sendiri bisa bervariasi banyak tergantung pada faktor-faktor seperti tujuan antarmuka, karakteristik pengguna, dan karakteristik perangkat interface tertentu. Sebagai contoh, meskipun semua antarmuka pengguna harus dirancang untuk kemudahan maksimal penggunaan, ada beberapa pertimbangan lainnya, seperti efisiensi operasional, yang mungkin penting bagi pengguna internal yang dapat dilatih untuk menggunakan interface tertentu, dikombinasikan dan dioptimalkan untuk perangkat keras tertentu (misalnya, keyboard, mouse, dan layar resolusi tinggi besar). Tujuan sebuah user interface adalah mengkomunikasikan fitur-fitur sistem yang tersedia agar user mengerti dan dapat menggunakan sistem tersebut. Dalam hal ini penggunaan bahasa amat efektif untuk membantu pengertian, karena bahasa merupakan alat komunikasi tertua kedua gestur, yang dipakai orang untuk berkomunikasi sehari-harinya.

\section{HASIL DAN PEMBAHASAN Brainstorming}

Langkah pertama dalam proses perancangan UI \& UX Aplikasi Pencari Indekost adalah melakukan pengelompokan ide-ide dalam bentuk gambar yang disebut Brainstorming.

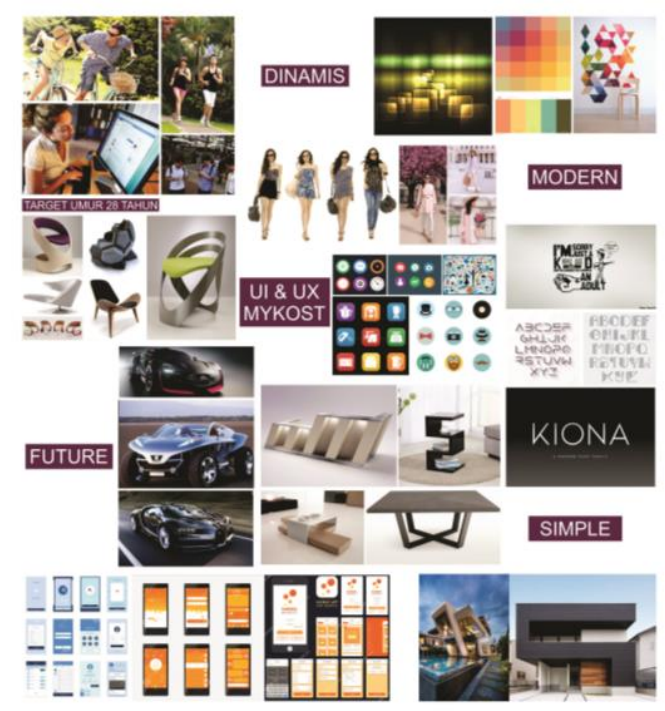

Gambar 2

Mapping Brainstorming

( Dicompare Oleh ferry fernando, 2018)

Pada Penjelasan brainstorming diatas terlihat arah dari perancangan UI \& UX aplikasi Pencari Indekost Di Kota Padangpanjang. Kesan Simple, Future, Modern dan Dinamis Akan terpakai dalam merancang nantinya. Selain itu penulis juga melakukan survey kepada masyarakat yang memakai media social. Dari hasil survey itu, sebagian Masyarakat merasa nyaman dalam menggunakan media social Instagram, Whatapps dan Facebook, karena lemih mudah dipahami dan simple.

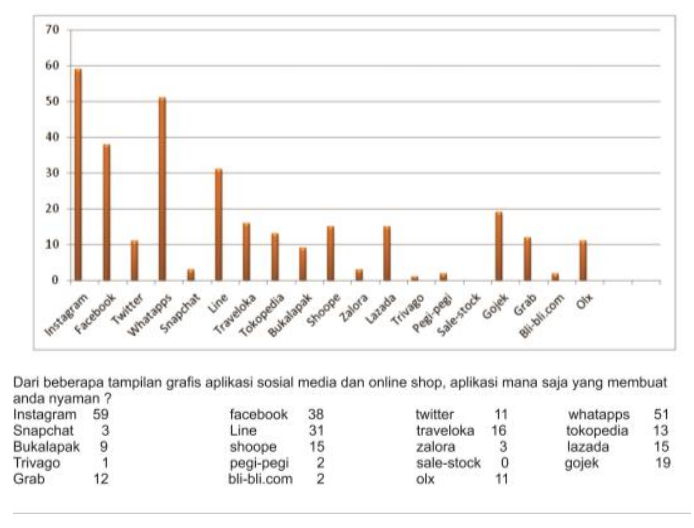

Gambar 3

Survey Visual Grafis Medsos \& Online Shop (Survey Oleh ferry fernando, 2018) 


\begin{abstract}
Perancangan Logo Aplikasi Pencari Indekost

Sebelum merancang UI \& UX aplikasi pencari indekost alangkah baiknya terlebih dahulu merancang logo (identitas) aplikasi agar nantinya bisa menghasilkan rancangan yang memiliki satu kesatuan yang utuh (unity). Perancangan logo aplikasi ini lebih menitikberatkan kepada bentuk campuran berupa gabungan logo type dan logo gram agar tercipta logo yang komunikatif dan visual yang memiliki kesatuan bentuk antara satu dan lainnya.
\end{abstract}

\section{Identitas Logo}

Dibutuhkan proses identitas sebelum masuk ketahap sketsa. Identitas ini berfungsi untuk menentukan visual dan karakter apa saja yang akan dimunculkan pada logo aplikasi nantinya. Dengan cara tersebut diharapkan visual dan karakter dapat sesuai dengan hasil riset dan analisa di lapangan. Berdasarkan hal tersebut ditemukan nama yang tepat untuk mewakili aplikasi ini yaitu MYKOST.

MYKOST yang memiliki arti kostan saya bermetamorfosis menjadi tempat yang enak, nyaman dan bersahabat. Kedekatan emosional didapatkan ketika MYKOST diutarakan kepada orang yang mendengarkannya. Sebuah indekost harus mencerminkan kenyamanan antara pemilik dan penyewanya agar ketika berada didalamnya suasana enak dan bersahabat tercipta dengan sendirinya.

\section{Picture Mark}

Proses lanjut setelah mendapatkan nama dari aplikasi pencari indekost adalah proses sketsa manual yang dilakukan diatas kertas atau disebut proses Picture Mark. Sketsa di peroleh dari penyederhanaan gambar yang merupakan bentuk visual dari konsep perancangan. Selanjutnya sketsa yang telah diperoleh dikembangkan dalam bentuk digital.

a. Studi Alternatif Sketsa Picture Mark

- Sketsa
Belah ketupat

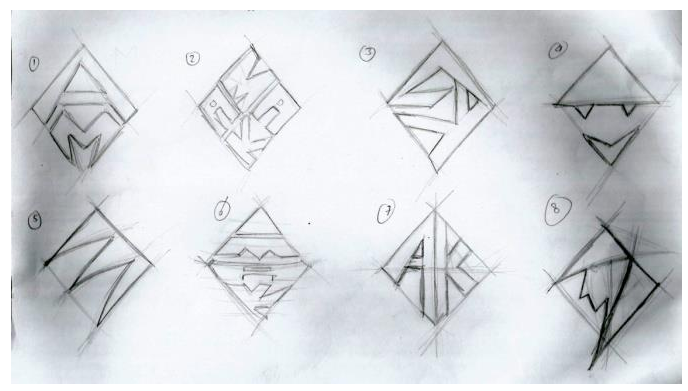

Gambar 4

Sketsa studi Picture Mark 1

(Dibuat Oleh ferry fernando, 2018)

\section{Segitiga}

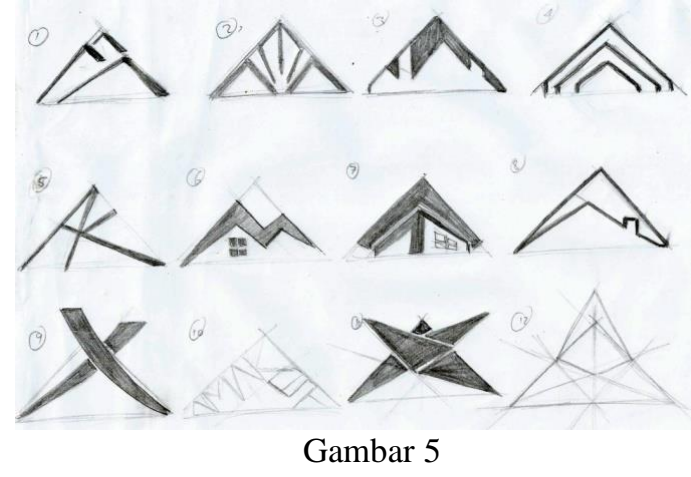

Sketsa studi Picture Mark 2

(Dibuat Oleh ferry fernando, 2018)

Lingkaran

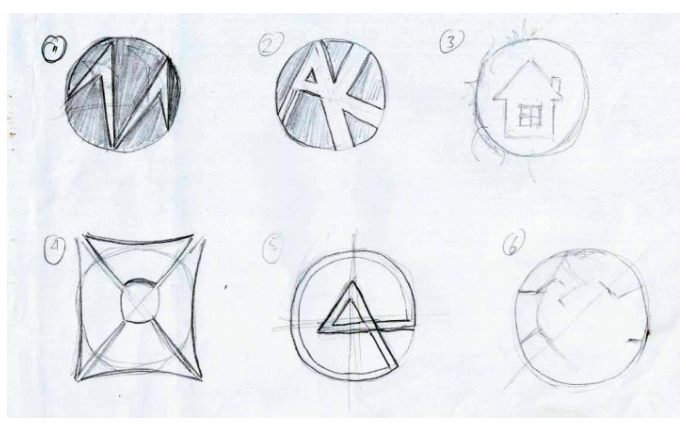

Gambar 6

Sketsa studi Picture Mark 3

(Dibuat Oleh ferry fernando, 2018) 
Segienam

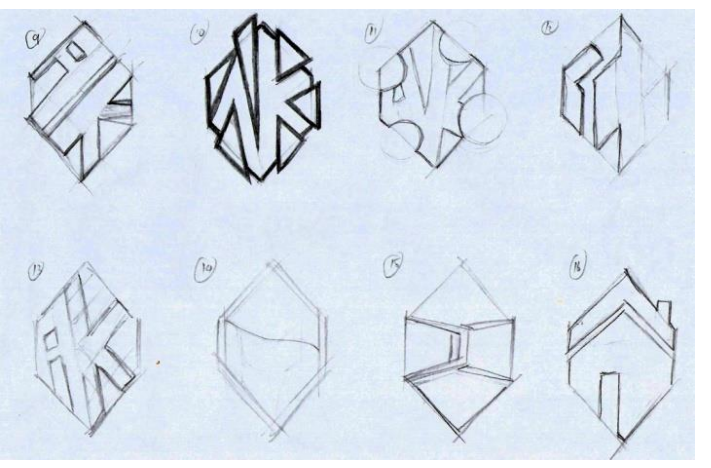

Gambar 7

Sketsa studi Picture Mark 4

(Dibuat Oleh ferry fernando, 2018)

\section{b. Alternatif Picture Mark Digital}

Setelah perancangan sketsa manual selesai terpilihlah beberapa alternative Picture Mark. Selanjutnya sketsa terpilih masuk pada tahap komputerisasi atau perancangan sketsa manual dalam bentuk digital. Nantinya hasil digital kembali akan di pilih untuk mendapatkan bentuk visual yang tepat dan cocok untuk perancangan UI \& UX Aplikasi pencari indekost di Kota Padangpanjang.

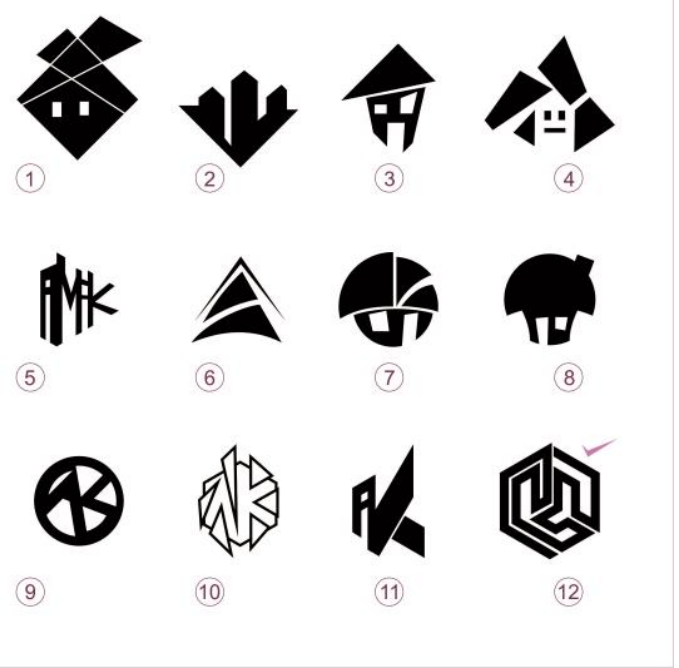

Gambar 8

Alternatif Picture Mark Komputerisasi

Alternatif terpilih bertanda ceklis (Dibuat Oleh ferry fernando, 2018)

\section{c. Sketsa Terpilih}

Sketsa yang telah melalui tahap digital atau komputerisasi akan di kelompokan kembali dan diseleksi lagi untuk mendapatkan hasil desain akhir dari logo.
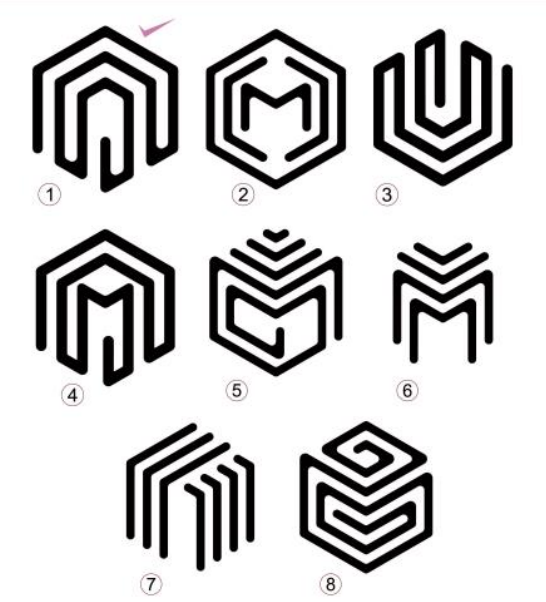

\section{Gambar 9}

Alternatif Picture Mark pengembangan Komputerisasi

Alternatif terpilih bertanda ceklis

(Dibuat Oleh ferry fernando, 2018)

d. Final Picture Mark

Didapatlah bentuk final Picture Mark berupa visual "rumah" yang garisnya terhubung menuju titik fokus di tengah.membentuk sebuah kubus yang memiliki sisi enam buah.

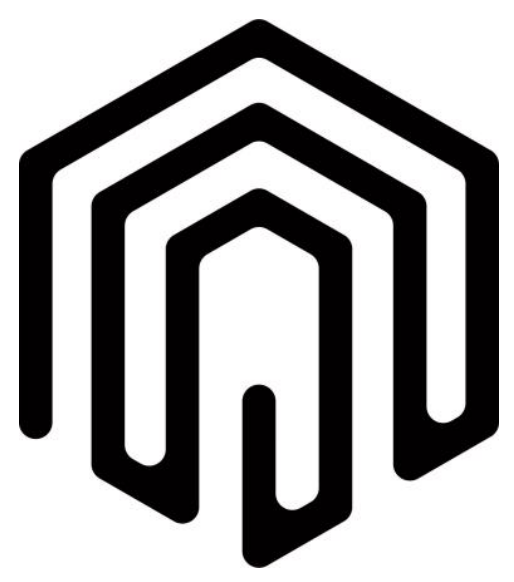

Gambar 10

Final Picture Mark

(Dibuat Oleh ferry fernando, 2018) 


\section{Studi Tipografi}

Setelah bentuk visual logo diperoleh selanjutnya masuk pada tahap pemilihan font melalui tahap studi tipografi. Diatas sudah disinggung sedikit bahwa logo untuk aplikasi pencari indekost memakai gabungan antara logo type dan logo gram. Untuk itulah dengan memilih tipografi yang tepat, layout yang baik, warna, dan bentuk yang sesuai, diyakini mampu menguatkan isi pesan visual dan pesan verbal dari aplikasi MYKOST

Berikut jenis tipografi aplikasi MYKOST yang diterapkan dalam perancangan UI \& UX antara lain :
a. MYKOST (Terpilih)
Jenis font ini bernama arkitech
b. MYKOST
Jenis font ini bernama Futurama
Bold Font
c. MYKOST
Jenis font ini bernama Futurama
Klondike Font
d. MYKOST
Jenis font ini bernama Futurama Planet Kosmos
e. MYKOST
Jenis font ini bernama Futurama Velocity

Pada perancangan ini tipografi yang digunakan untuk MYKOST adalah jenis font Arkitech. Dimana font ini memiliki lekuk padda bagian sudut font dan selaras dengan bentuk logo gramnya. Sedangkan untuk bodytext aplikasi nantinya memakai jenis font ubuntu.
a. login, signup, email, search Jenis font ini bernama BN Dragon
b. login, signup, email, search Jenis font ini bernama Continuum Light
c. login, signup, email, search Jenis font ini bernama Ebrima
d. login, signup, email, search Jenis font ini bernama Helvetica
e. login, signup, email, , search (Terpilih) Jenis font ini bernama Ubuntu - Title

Setelah bodytext terpilih selanjutnya ada beberapa jenis-jenis tagline untuk aplikasi MYKOST diantaranya adalah :

a. Aman,Nyaman dan Sejuk

b. Indah dan Cantik

c. Nikmati Kepuasan Anda Mencari Hunian

d. homy \& friendly

e. Cepat dan Terpercaya

f. Life is Wonderful (Terpilih)

\section{Desain Alternatif Logo}

Untuk masuk ketahap final desain pilih salah satu alternative desain logo yang nantinya dapat dikembangkan lebih lanjut.
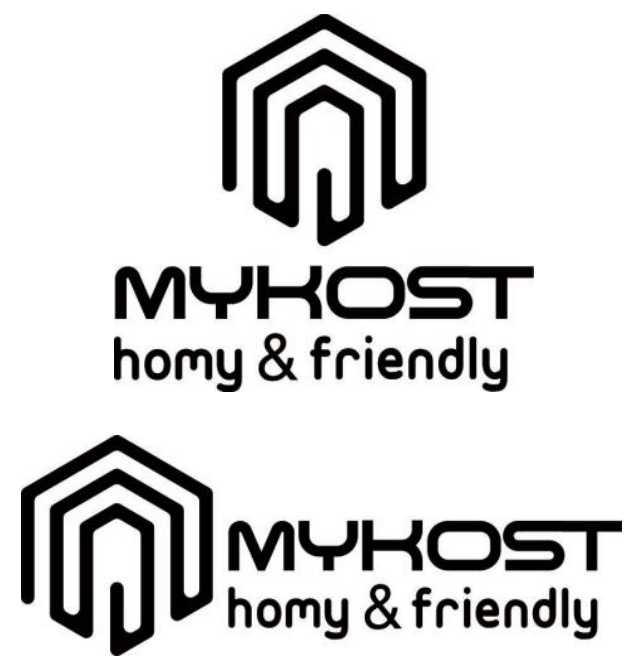

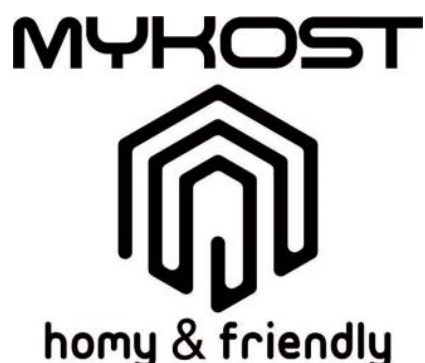



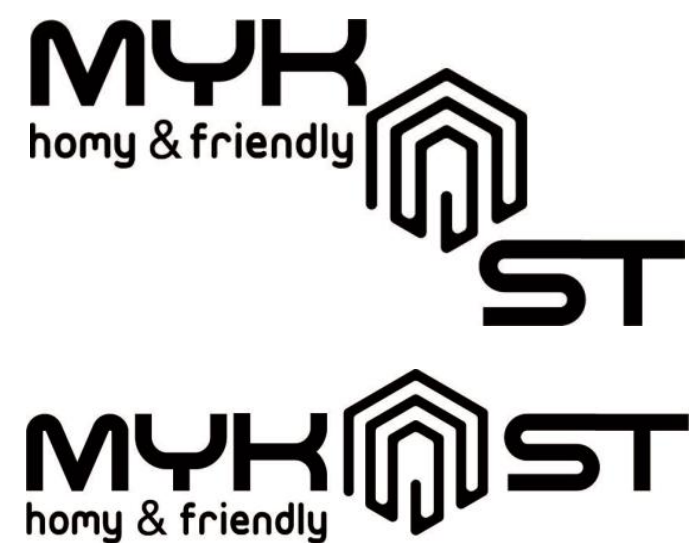

Gambar 11

Desain Alternatif Logo

(Dibuat Oleh ferry fernando, 2018)

\section{Final Logo (B/W)}

Berikut final B/W (black / white) logo yang telah terpilih

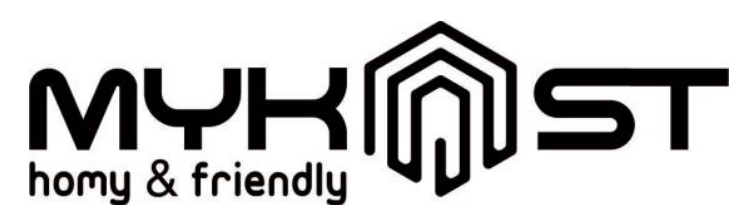

Gambar 12

Final Logo

(Dibuat Oleh ferry fernando, 2018)

Orisinal Logo gram yang berlandaskan dari bentuk segi enam dengan paduan garis yang tidak putus menjadikan logo lebih unik dan menarik. Perpaduan itu menciptakan bentuk baru yaitu atap rumah yang sangat indentik dengan indekost.

Estetis

Logo dirancang untuk menyampaikan kepada masyarakat bahwa aplikasi MYKOST hadir dengan rasa persahabatan, nyaman dan enak yang disederhanakan dalam bentuk atap rumah yang memiliki fungsi untuk melindungi siapapun yang berada didalamnya. Dinamis

Logo yang memiliki kesan lengkung tanpa ada sudut runcing memberikan kesan dinamis tidak kaku. Setiap garis terhubung satu dengan yang lainnya. Kesatuan itulah yang akan dihadirkan oleh aplikasi MYKOST dalam melayani setiap masyarakat yang ingin mendapatkan fasilitas yang enak dan bersahabat. Sehingga aplikasi dapat dinikmati senyaman mungkin.

Komunikatif Logo MYKOST yang terdiri dari kesatuan logo type dan logo gram dapat menciptakan komunikasi yang baik dengan para usernya. Setiap informasi yang dibutuhkan nantinya memberikan keterhubungan satu dengan yang lain. Garis hitam menunjukan ketegasan dan keharmonisan dalam memberikan kenyamanan dalam berselancar menggunakan aplikasi tersebut.

\section{Perancangan Layout UI \& UX Story Telling}

Sebelum merancang layout UI, terlebih dahulu harus membuat storytelling mengenai aplikasi MYKOST ini. Tujuan agar langkah setiap halaman aplikasi dapat dipahami dan dimengerti oleh masyarakat. Menurut Echols (dalam aliyah, 2011) storytelling terdiri atas dua kata yaitu story berarti cerita dan telling berarti penceritaan. Penggabungan dua kata stortytelling berarti penceritaan cerita atau menceritakan cerita.

Berikut storytelling aplikasi MYKOST :

- Tampilan pertama, Kemunculan logo dengan proses loading.

- Tampilan kedua tentang pemilihan login dan signup.

- Tampilan ketiga tetang proses login dengan mengisi nama dan password.

- Tampilan keempat tentang proses signup dengan mengisi alamat email, nama, password dan retype password.

- Tampilan kelima tentang home yang mana pada home ini terdapat menu pencarian, gallery, tipe indekost, map, dan bantuan.

- Tampilan keenam tentang menu pencarian yang mana terdapat daerah pencarian indekost sesuai filternya seperti nama pemilik indekost, alamat, kecamatan, kota.

- Tampilan ketujuh tentang gallery yang mana terdapat berbagai macam foto indekost lengkap dengan fasilitasnya.

- Tampilan kedelapan tentang tipe indekost yang mana ada spesifikasi dari tipe indekost mulai yang rendah, sedang dan 
tinggi. Selain itu terdapat juga penjelasan mengenai status dari indekost tersebut.

- Tampilan kesembilan tentang map yang mana terlihat posisi dari indekost sekitar kota padangpanjang.

- Tampilan kesepuluh tentang bantuan yang mana terdapat kontak person dari admin mykost dan tutorial mengunakan aplikasi.

Desain Layout User Interface (UI) dan User Experience (UX)
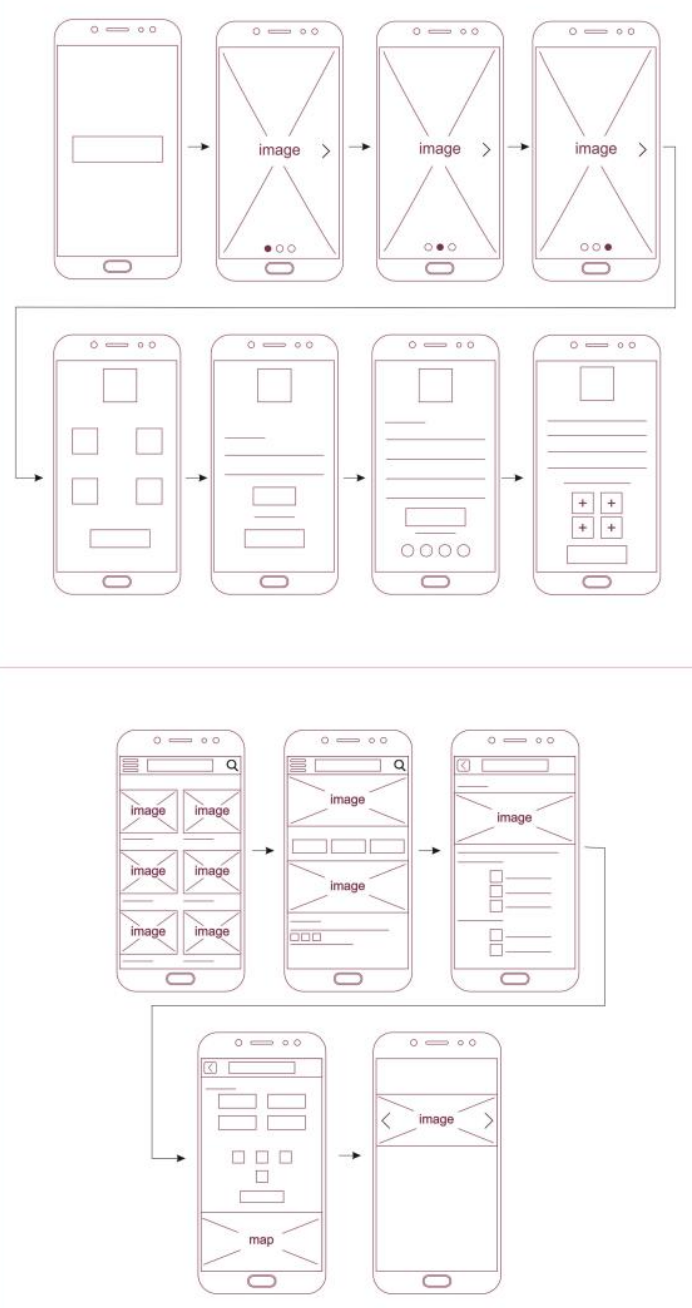

Gambar 13

Alternatif layout UI \& UX

(Dibuat Oleh ferry fernando, 2018)

\section{Studi Icon}

Studi icon dalam aplikasi MYKOST lebih menitik beratkan kepada bentuk outline/garis.
Garis memiliki kemampuan untuk mengungkapkan suasana. Suasana yang tercipta dari sebuah garis terjadi karena proses stimulasi dari bentuk-bentuk sederhana yang sering kita lihat disekitar kita. Garis juga memiliki dimensi seperti tebal,tipis, panjang dan pendek. Pemilihan icon untuk aplikasi MYKOST memberikan kesatuan antara logo dimana bentuk logo lebih kepada bentuk garis yang tebal dan saling berhubungan satu dengan lainnya.

Beberapa icon yang ada dalam aplikasi MYKOST antara lain :
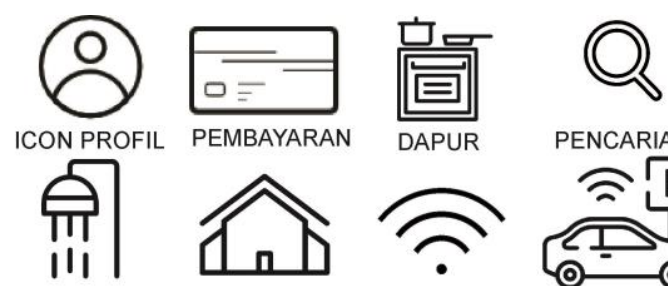

PEMBAYARAN
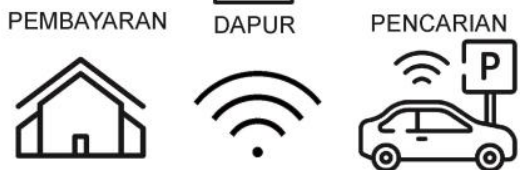

KAMAR MANDI

HUNIAN

FREE WIFI

PARKIR MOBIL
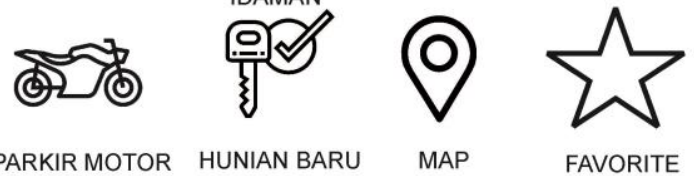

PARKIR MOTOR HUNIAN BARU

MAP

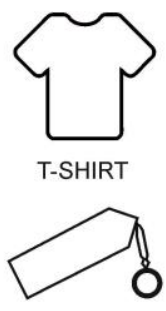

GANTUNGAN $\mathrm{KUNCI}$

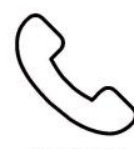

CONTAC PERSON

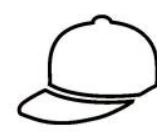

TOPI

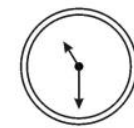

JAM DINDING
MUG

Gambar 14

Studi Icon

(Dibuat Oleh ferry fernando, 2018) 
Ferry Fernando, PERANCANGAN USER INTERFACE (UI) \& USER EXPERIENCE (UX) APLIKASI PENCARI INDEKOST DI KOTA PADANGPANJANG

Final Layout UI \& UX MYKOST

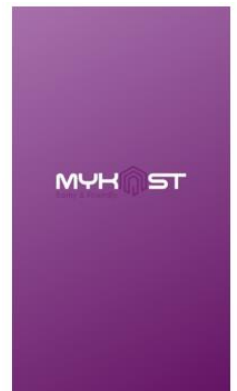

Open page

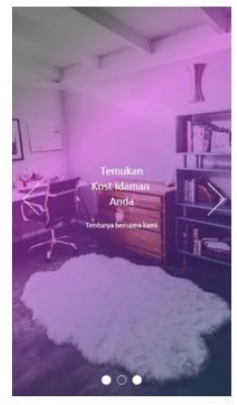

Landing welcoming 2 Landing welcoming 3
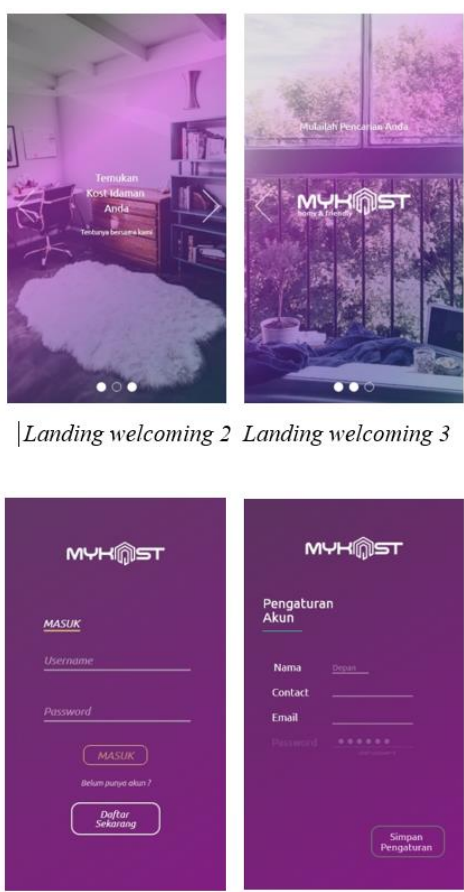

Login Page
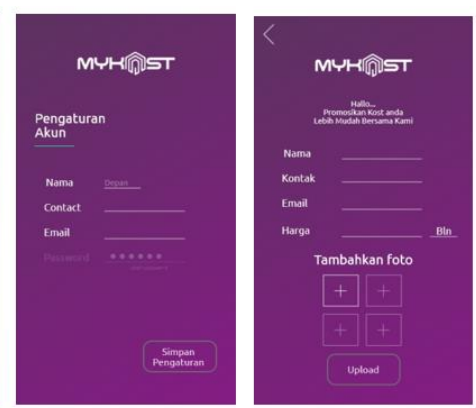

Account Setting Page Account Setting Page 1

Gambar 15

Final User Interface (UI) \& User Experience (UX) MYKOST

(Dibuat Oleh ferry fernando, 2018)
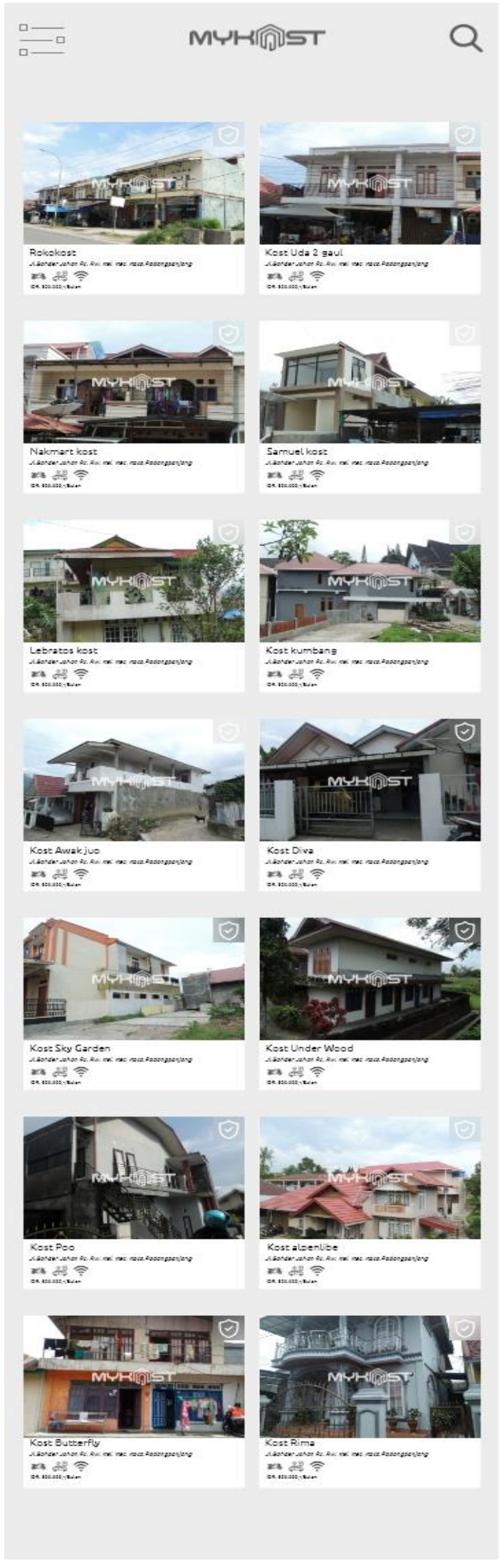


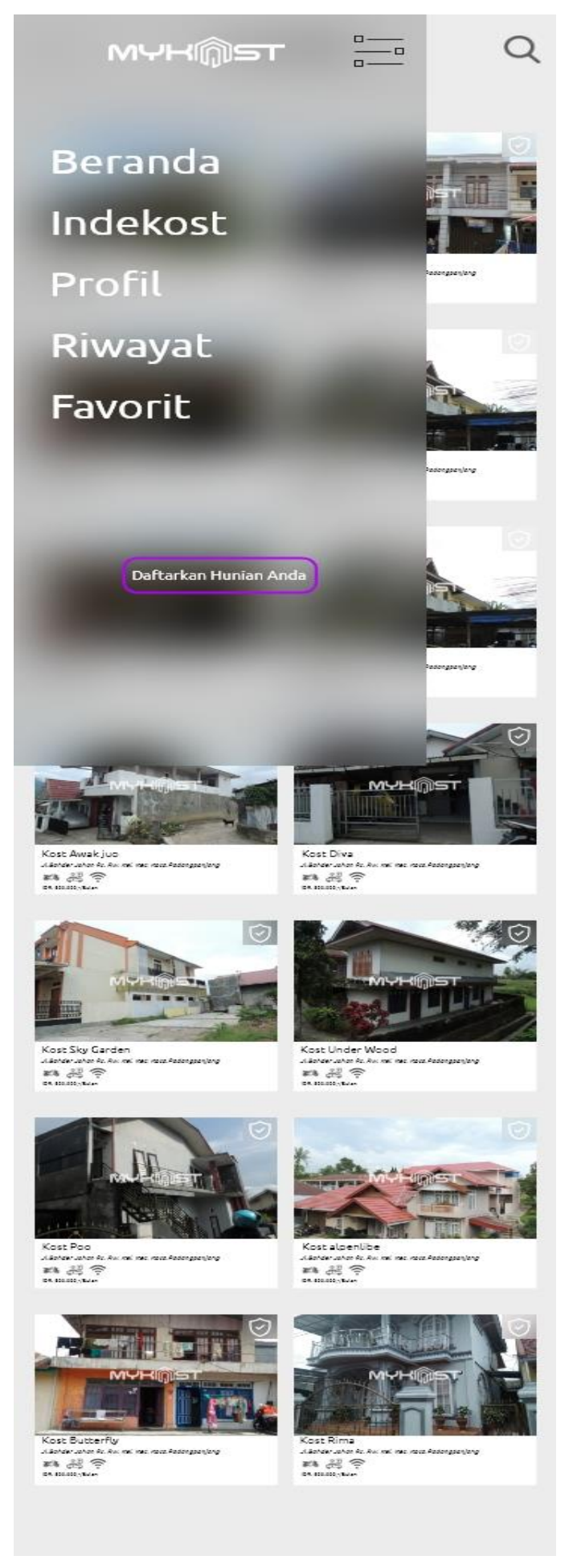

Indekost Indekost Sidebar

Gambar 16

Final User Interface $(U I) \&$ User Experience (UX) MYKOST

(Dibuat Oleh ferry fernando, 2018)

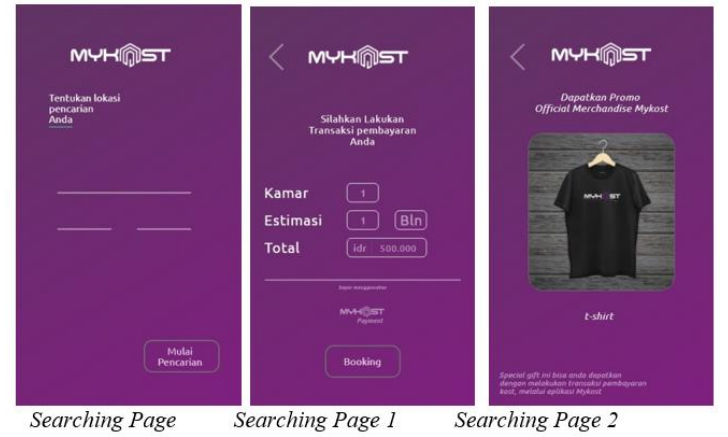

Gambar 17

Final User Interface (UI) \& User Experience (UX) MYKOST

(Dibuat Oleh ferry fernando, 2018)

\section{PENUTUP}

Setelah melalui proses perancangan UI \& UX Aplikasi Pencari Indekost yang bernama MYKOST dapat disimpulkan sebagai berikut :

1. Masyarakat Kota Padangpanjang memiliki peluang untuk terbantu dalam mempromosikan indekost yang mereka miliki dengan menggunakan aplikasi MYKOST.

2. Para pencari indekost berpeluang tidak lagi bersusah payah dalam mengetahui informasi dan fasilitas yang ada pada indekost.

3. Hadirnya aplikasi MYKOST memberikan peluang kepada pemerintah daerah untuk menata dan mengelola indekost yang tersebar di Kota Padangpanjang agar dapat menjadi pemasukan bagi pemerintah kota.

4. Perancangan UI \& UX aplikasi MYKOST dapat memberikan kenyamanan kepada pemakai media social dalam mencari setiap informasi yang ada tentang indekost di Kota Padangpanjang.

\section{KEPUSTAKAAN}

Beaird, Jason. 2007. The Principles of Beautiful Web Design. Jakarta: ANDI.

Garett, Jesse James .2011.The Elements Of User Experience : User-Centered Design for the Web. Berkeley 
John W. Satzinger, Robert B. Jackson, Stephen D. Burd. 2012. Introduction To System Analysis And Design. Boston John dan David Colett. 2006. Black and White Photography Technique.

Jonatan Sarwondo \& Harry Lubis.2007. Metode Riset untuk Desain Komunikasi Visual. Yogyakarta: C.V Andi Offset.

Kamus Besar Bahasa Indonesia

Kusrianto, Adi. 2009. Pengantar Desain Komunikasi Visual. Yogyakarta: ANDI.

Lebond, Bayu. 2017. "Colour Therapy". Pengaruh Warna Bagi Manusia

MANDASARI, D. A. (2015). Analisis SosioSpasial Kost Yang Mempengaruhi Preferensi Kost Mahasiswa Di Lingkungan Kampus Ums. Universitas Muhammadiyah Surakarta.

O'Galitz, Wilbert. 2002 The Essential Guide of User Interface Design. Indiana polis:Wiley Publishing Sugiono, Dendy. 2008. Kamus Besar Bahasa Indonesia Pusat Bahasa. Jakarta: Gramedia Pustaka Utama.

Sachari, Agus. 2002. Sosiologi Desain. Bandung:ITB

Wiryawan, Mendiola B. 2011.User Experience Sebagai Bagian Pemikiran Desain Dalam Pendidikan Tinggi Desain Komunikasi Visual. Jurnal Humaniora Vol 2 No 2.

Sumber Lain :

Perda, No 8.2011. Pajak Daerah ISO ( International Organization for Stardardization) 9241-210 http://www.ablok.com/en/reactable.html November 2017, Jam 20.30)

http://blog.re.or.id/antarmuka-pemakai-userinterface.htm (5 November 2017, Jam 20.30)

http ://www.pasbana.com, 27 Desember 2016, 10.15 (5 November 2017, Jam 20.30)

Playstore android. (5 November 2017, Jam 20.30) 